\title{
Comparative analysis of Qualitative and Quantitative Phytochemical screening, in vitro antioxidant and antibacterial activity of Mangifera indica and Artocarpus heterophyllus
}

\author{
T.Manimekalai $^{{ }^{*}}$ \& Dr. P. Chitra ${ }^{2}$ \\ 1 - M.Phil Scholar, 2 - Associate professor and Head, Department of Biochemistry, Sri Ramakrishna \\ College of Arts and Science for Women, Coimbatore.
}

\begin{abstract}
Medicinal plants have known to play a wide role in the development of human culture. Artocarpus heterophyllus and Mangifera indica are the well known evergreen tropical fruiting tree families abundantly grown in Asia. Different parts of both the tress such as bark, leaves, fruits and flowers are used in traditional medicine. The present study aims to screen the qualitative and quantitative phytochemical present, in-vitro antioxidant and anti-microbial activity of Artocarpus heterophyllus and Mangifera indica leaf extracts and combined extract of both the leaves. The qualitative phytochemical results indicated the presence of phytochemicals such as alkaloids, flavonoids, phytosterols, tannins and saponins. The quantitative phytochemical results revealed that M.indica have high phenolic and flavonoid content. The Combined extract showed significant antioxidant activity when compared to both the extracts. All the extracts showed significant antimicrobial activity.
\end{abstract}

Keywords

Antimicrobial, Anti-oxidant, Phytochemicals, Artocarpus heterophyllus, Mangifera indica.

Introduction

Mangoes belong to the genus Mangifera of the family Anacardiaceae. Mango has cultivated and adapted throughout the tropics and subtropics. Mango fruit, seed, leaves, bark and roots have diverse phytochemical constituents including polyphenolic antioxidants, flavonoids, triterpenoids, micronutrients and reported to exhibit diverse medicinal properties and health benefits [1]. Artocarpus heterophyllus, belongs to the mulberry family, Moraceae and widely is consumed in south-east Asia and Africa [2]. It is well known for its antibacterial, antifungal, antidiabetic, anti-inflammatory, and antioxidant activities [3]. Artocarpus heterophyllus leaves and stem barks are used in traditional medicine to treat several diseases include hypertension, diabetes, cancers, anemia, asthma, dermatosis and diarrhoea [4]. 
Plants provide not only essential nutrients needed for life, but also other bioactive phytochemicals that contribute to health promotion and disease prevention. Several studies strongly suggest that ingesting these phytochemicals can help to improve health [5]. The biologically active metabolites of medicinal plants and their possible therapeutic potential has become a subject of active investigation [6]. Plant based medicines are becoming popular because of their lesser toxicity and side effects [7]. Antioxidants significantly delay or prevent oxidation of oxidizable substrates when present at lower concentrations than the substrate. Since the antioxidant potential of plants has received a great deal of attention because increased oxidative stress has been identified as a major causative factor in the development and progression of several life threatening diseases in humans [8].

Recently, researchers have focused on increasing human infections caused by bacteria and fungi. Medicinal plants represent a rich source of antimicrobial agents. Because microorganisms have developed resistance to many antibiotics, the use of plant extracts and their isolated compounds as a resistant against microorganisms has been increased. Antibacterial activity of different plant extracts using different solvents was documented in the literature [9]. Plants produce secondary metabolites which are a rich source of antioxidant and antibacterial properties.

Materials and Methods

\section{Plant Collection}

The leaves of Mangifera indica and Artocarpus heterophyllus were collected from the local areas of Erode and were authenticated by Botanical Survey of India, Southern Regional Centre, Coimbatore.

\section{Extract Preparation}

The collected leaves were washed with water and shade dried for about 20 days. The dried leaves of Mangifera indica and Artocarpus heterophyllus were crushed to coarse powder and then grinded using an electric grinder. Then $5 \mathrm{~g}$ of each powdered sample was suspended $50 \mathrm{ml}$ of distilled water and kept in a shaker for overnight and then filtered. The Combined extract was prepared by mixing equal amount of both the extracts.

Qualitative Phytochemical Analysis

Test for Alkaloids (Wagner's test): About few ml of extract was treated with 4-5 drops of Wagner's reagent. The formation of reddish brown precipitate confirms the presence of Alkaloids[10]. 
Test for Phenol (Ferric chloride test): About $2 \mathrm{ml}$ of the extract was treated with few drops of ferric chloride solution and observed. The formation of deep blue / black colour indicates the presence of phenols[10].

Test for reducing sugars (Fehling's Test): To $1 \mathrm{ml}$ of the extract added few drops of Fehling's reagent and the mixture was boiled in a boiling water bath for 10 minutes and observed for the appearance of blue colour[11].

Test for Saponins (Foam test): To $2 \mathrm{ml}$ of extract added $6 \mathrm{ml}$ of water in a test tube. The mixture was shaken vigorously and observed for the formation of persistent foam for few seconds. The presence of foam confirms the presence of saponins[10].

Test for Flavonoids: Few drops of $1 \%$ aluminium solution were added to a portion of each extract. A yellow colouration observed indicates the presence of flavonoids[12] .

Test for Phytosterols (Salkowski's Test): One $\mathrm{ml}$ of the extract was treated with $2 \mathrm{ml}$ of chloroform and few drops of acetic anhydride were added. To that mixture added equal amount of concentrated sulphuric acid was added. The formation of bluish green colour indicates the presence of phytosterols[11].

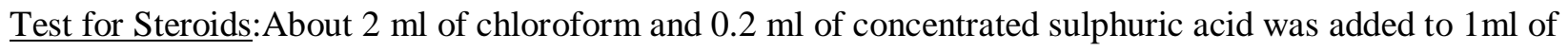
extract. The formation of red colour precipitate indicates the presence of steroids[11].

Test for Tannin: To about $1 \mathrm{ml}$ of extract added few drops of $0.1 \%$ of ferric chloride solution. The presence of tannin is confirmed by the formation of dark green or blue color[12].

Test for cardiac glycosides: To $1 \mathrm{ml}$ of plant extract added few $\mathrm{ml}$ of concentrated sulphuric acid. Formation of red colour indicates the presence of glycosides[13].

Test for Terpenoids: To $2.0 \mathrm{ml}$ of chloroform added $5 \mathrm{ml}$ of the extract. To the mixture added $3 \mathrm{ml}$ of concentrated sulphuric acid. The appearance of reddish brown coloration at the interface shows the presence of terpenoids[13].

Quantitative Phytochemical Analysis

Determination of Phenol Content:

The total phenol content in the extracts was determined by slightly modified Folin and Ciocalteu method. To about $1 \mathrm{ml}$ of the leaf extracts added $0.2 \mathrm{ml}$ of Folin Ciocalteu phenol reagent mixture and 1 $\mathrm{ml}$ of $20 \%$ sodium carbonate. The total content is then incubated at $45^{\circ} \mathrm{C}$ in a water bath for 45 minutes. 
The absorbance was then measured at $765 \mathrm{~nm}$. Gallic acid dilutions were used as standard solutions. The results of phenols are expressed in terms of Gallic acid in $\mathrm{mg} / \mathrm{ml}$ of extract [14].

\section{Determination of Flavonoid Content:}

Analysis of flavonoid content was done using the aluminium chloride colorimetric assay with slight modifications. The assay is based on the formation of an acid-stable complex of aluminium chloride with the C-4 keto group and either the C-3 or C-5 hydroxyl group of flavonoids. $1 \mathrm{ml}$ of leaf extracts were mixed with $0.1 \mathrm{ml}$ of $10 \%$ aluminium chloride, $0.1 \mathrm{ml}$ of $1 \mathrm{M}$ Potassium Sodium tartarate and $2.8 \mathrm{ml}$ distilled water. Then the mixture is incubated at room temperature for 30 minutes. Absorbance of the yellow-green complex was measured at $415 \mathrm{~nm}$. Quercetin was used as standard and analysed as above. Flavonoid content of the leaf extracts were expressed as mg quercetin equivalents per gram dried weight (mg QE/g dried weight) [15].

\section{In-vitro Antioxidant Assay}

Hydrogen Peroxide Scavenging Assay:

The ability of the extract to scavenge hydrogen peroxide was determined in accordance with standard method with slight modifications. A hydrogen peroxide solution ( $2 \mathrm{mmol} / \mathrm{l})$ was prepared in phosphate buffer ( $\mathrm{pH}$ 7.4). About $2 \mathrm{ml}$ of $20 \mathrm{Mm}$ Hydrogen peroxide was taken as a control. Then the experimental sample tubes were added with $0.5 \mathrm{ml}$ of the extract. Then $2 \mathrm{ml}$ of $\mathrm{H}_{2} \mathrm{O}_{2}$ reagent was added to all the test tubes, mixed well and added $0.9 \mathrm{ml}$ of Ethanol. The tubes were incubated for a short period of 10 - 15 minutes at room temperature. Then the absorbance of samples was read at $230 \mathrm{~nm}$ against a blank solution containing phosphate buffer without hydrogen peroxide and compared with ascorbic acid as reference compound [16].

\%inhibition of $\mathrm{H}_{2} \mathrm{O}_{2}$ Scavenging effect $=($ Abs Control - Abs Extract $) /$ Abs Control $\times 100$

Superoxide radical Scavenging Assay:

Superoxide dismutase (SOD) activity was determined by the inhibition in photoreduction of nitrobluetetrazolium by the SOD enzyme. To the $0.1 \mathrm{ml}$ of sample added $1 \mathrm{ml}$ of the reaction mixture I ( $1 \mathrm{ml}$ of $50 \mathrm{mM}$ PBS, $0.075 \mathrm{ml}$ of $20 \mathrm{mM}$ L Methionine, $0.04 \mathrm{ml}$ of $10 \mathrm{mM}$ hydroxyl amine hydrochloride, and $0.1 \mathrm{ml}$ of $50 \mathrm{mMEDTA}$ ) and incubate the sample at $30^{\circ} \mathrm{C}$ for 5 minutes. After incubation added 50 $\mathrm{M}$ riboflavin and the sample was allowed to expose under 200W fluorescent light. 
$1 \mathrm{ml}$ of the reaction mixture II (1\% Sulphanilamide in 5\% phosphoric acid) was added and the measurement was read at 543nm under spectrophotometer [17].

Percentage inhibition $=($ Abs Control - Abs Extract $) /$ Abs Control $\times 100$

Total Antioxidant Assay:

The total antioxidant capacity of the leaf extracts was assessed spectrophotometrically by the phosphomolybdenum method. $0.5 \mathrm{ml}$ of each sample extract was mixed with $0.5 \mathrm{~mL}$ reagent solution (0.6 M H2SO4, 28 mM Sodium phosphate and 4 mM Ammonium molybdate). The blank solution contained 1 $\mathrm{mL}$ reagent solution only. The mixtures were incubated at $50^{\circ} \mathrm{C}$ in a water bath for $150 \mathrm{~min}$. After the mixture had cooled to room temperature, absorbance was measured at $695 \mathrm{~nm}$. Total antioxidant capacity was expressed as tannic acid equivalent (TAE) [18].

\section{Antimicrobial Activity}

Selection of Bacteria

Four pathogenic bacterial strains were used in this study for assessing the antibacterial activity of leaf extracts, including the Gram-negative and Gram-positive strains namely; Escherichia coli, Staphylococcus aureus, Pseudomonas aeruginosa and Klebsiella pneumoniae. Bacterial strains were cultured at $37^{\circ} \mathrm{C}$ and maintained on nutrient agar slant at $4^{\circ} \mathrm{C}$. The antibacterial activity of the leaf extracts was carried out using the agar well diffusion method.

Agar well Diffusion Method

Antibacterial activity of the sample was identified by using agar well diffusion method against the bacteria. Mueller Hinton agar (39gm in 1000ml) was prepared and poured into the petri dishes. After the agar is set, $70 \mu \mathrm{l}$ of the bacterial culture (E.coli, S.aureus, K.pneumoniae, P.aeruginosa) is swabbed using cotton swab and well were made with cork-borer followed by the sample and control. The leaf extracts $(20 \mu \mathrm{l})$ were added to the separate wells. Antibiotic disc (Levofloxacin 30mcg) was placed as a positive control and distilled water was placed in a well as negative control. The plates were incubated at $37^{\circ} \mathrm{C}$ for $24 \mathrm{hrs}$. After incubation anti - bacterial activity of the sample was measured based on the zone of inhibition in mm [19]. 


\section{Results and Discussion}

Qualitative Phytochemical Analysis

The extract of Mangifera indica and Artocarpus heterophyllus showed the presence of phenol, flavonoids, tannin, and terpenoids, alkaloid, phytosterol, saponins, steroids and cardiac glycosides. The Combined extract showed the presence of alkaloid, phenol, flavonoids, tannin, terpenoids, steroids, phytosterol, saponins.

This is in accordance with the study of phytochemicals done by Mohammed et al., 2016 in Mangifera indica which showed the presence of alkaloids, flavonoids, steroids and tannin in aqueous, ethanol and chloroform extracts [20].

\section{Table 1: Phytochemical analysis of M.indica, A.heterophyllus and its Combined Extract}

\begin{tabular}{|l|c|c|c|}
\hline Phytochemicals & M.indica & A.heterophyllus & Combined Extract \\
\hline Alkaloids & + & + & + \\
\hline Flavonoids & + & + & + \\
\hline Phenol & + & + & + \\
\hline Reducing sugar & - & + & - \\
\hline Tannins & + & + & + \\
\hline Saponin & + & + & + \\
\hline Phytosterol & + & - & + \\
\hline Steroids & + & - & + \\
\hline Terpenoids & + & + & + \\
\hline Cardiac glycosides & + & - & + \\
\hline
\end{tabular}

$(+)=$ presence of phytochemicals $(-)=$ absence of phytochemicals

Quantitative Determination of Phenol:

Gallic acid was used as standard for total phenolic acid content. The quantity of phenol present in the leaf extracts was presented in Figure 2.

Total phenolic content of the leaf extracts were $125 \mathrm{mg} \mathrm{GAE} / \mathrm{g}$ for Mangifera indica and 73 mg GAE/g for Artocarpus heterophyllus and $100 \mathrm{mg}$ GAE/g for the Combined Extract. The result 
indicated that the aqueous extract of M.indica possess high amount of phenol when compared to $A$. heterophyllus and Combined extract.

Phenolic compounds are strong antioxidants that have the ability to prevent the tissue damage caused by the free radicals [21]. Since the extracts contain significant amount of phenol content, it might be responsible for their antioxidant property.

Figure 2: Amount of Phenol in M.indica and A.heterophyllus leaf extracts and Combined extract

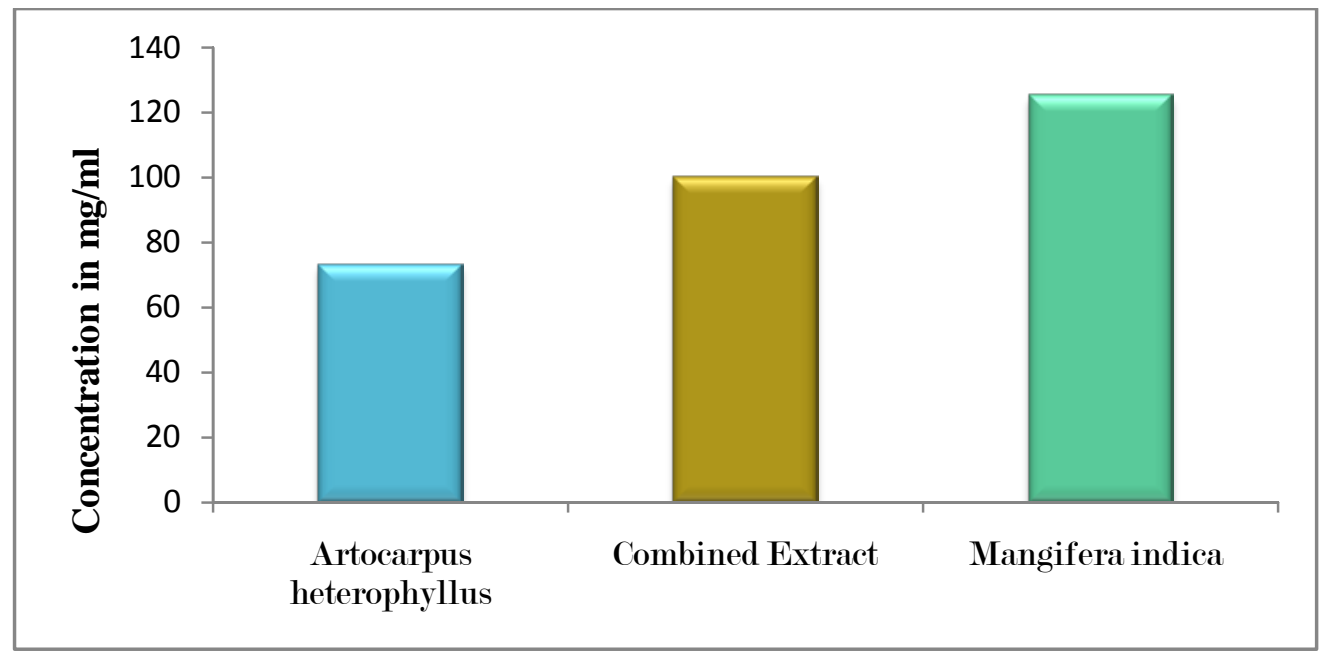

The analysis of phenol content in different Mangifera species by Fitmawati et al., 2020 revealed the presence of highest phenolic compounds of wild mangoes leaves of $M$. torquenda $(92.48 \mathrm{mg} / \mathrm{g})[22]$.

Quantitative Determination of Flavonoid:

Quercetin equivalent was the standard used to test the total flavonoid content. The amounts of flavonoid present in the aqueous extracts were found to be $720 \mathrm{mg}$ QE/g for M.indica and $540 \mathrm{mg}$ QE/g for G.superba and $700 \mathrm{mg}$ QE/g for Combined extract. The results reveal that M.indica contains more flavonoid content. The flavonoid present in the leaf extracts was represented in Figure 3.

The analysis of flavonoid content in different Mangifera species by Fitmawati et al., 2020 revealed the presence of the highest amount of flavonoid compounds were found in the bark and leaves of M. sumatrana (98.69 mg/g and $107.50 \mathrm{mg} / \mathrm{g}$, respectively) [22]. 
Figure 3: Amount of Phenol in M.indica and A.heterophyllus leaf extracts and Combined extract

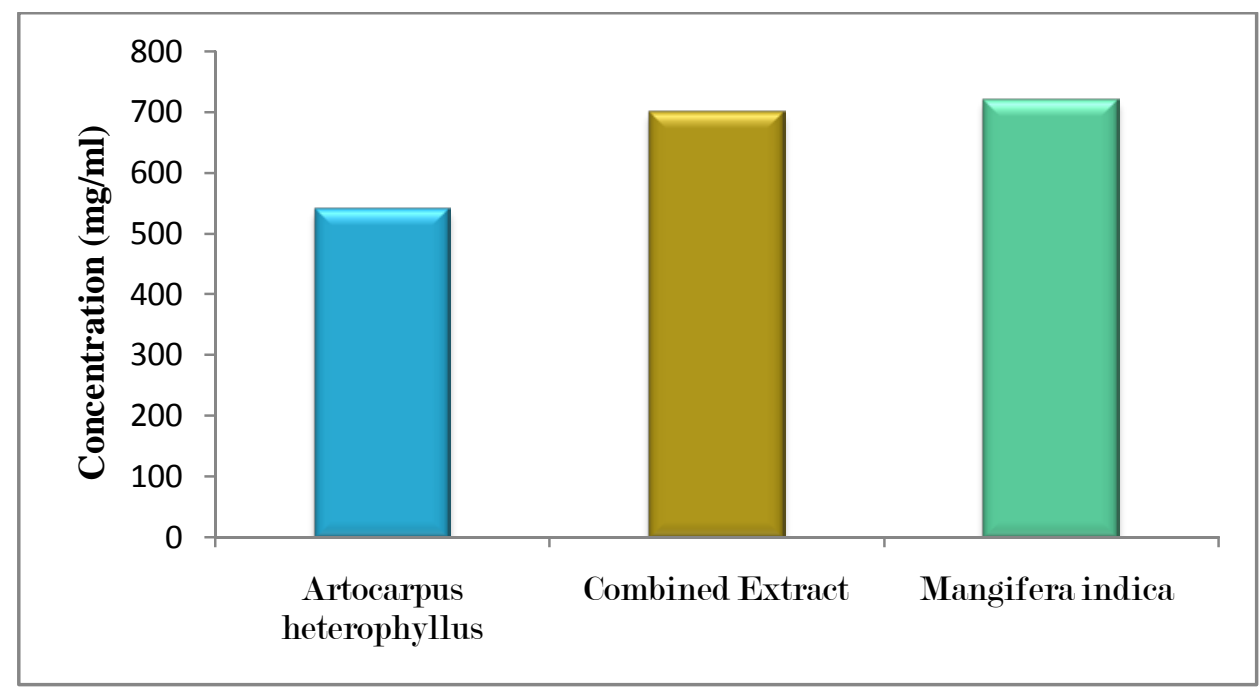

Flavonoids are water soluble polyphenolic compounds which are extremely common and wide spread in the plant kingdom as their glycosides. The flavonoids act through scavenging or chelating process and help in reducing the effect of antioxidants [23]. The flavonoid content present in the extracts may also contribute to their antioxidant activity.

\section{Invitro Antioxidant Assay}

Anti-oxidants works by intercepting with reactive oxygen species to quench the radicals and to produce less aggressive chemicals species likely to cause tissue damage. Much attention has been focused on the use of anti-oxidants because of their protective effect against damage from reactive oxygen species [24]. The Antioxidant activities of M.indica, A.heterophyllus and the Combined extract were determined using the Hydrogen peroxide scavenging, superoxide radical scavenging and Total antioxidant assay methods in the present study.

Hydrogen peroxide scavenging assay:

The Hydrogen peroxide radical scavenging capacities of the extracts were represented in Figure 4. 
Figure 4: Hydrogen peroxide activity of M.indica and A.heterophyllus and Combined extract

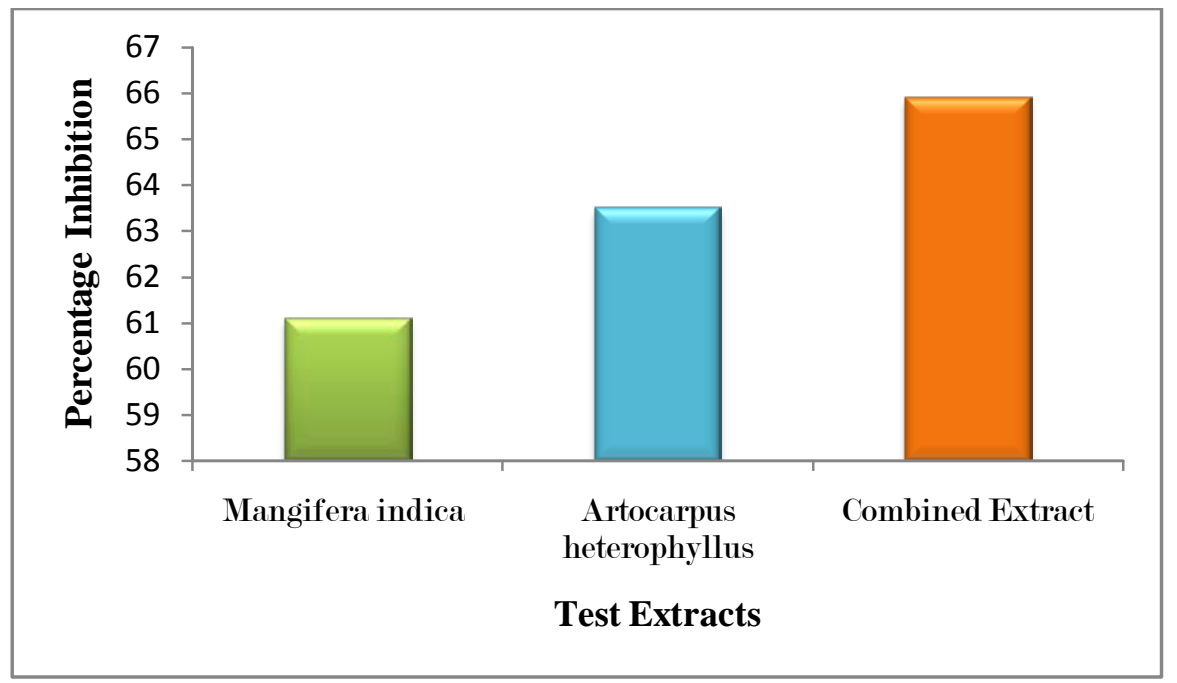

The results of the Hydrogen peroxide radical scavenging activity revealed that the Combined aqueous extract of M.indica and A.heterophyllus have effective hydroxyl radical activity when compared to individual leaf extracts with percentage inhibition of 91.1 per $\mathrm{ml}$ of the extract . Between aqueous extract of M.indica and A.heterophyllus, the hydrogen peroxide radical activity was found to be higher in A.heterophyllus extract.

Superoxide radical Scavenging Assay:

The results of the Superoxide radical scavenging assay resulted that the Combined aqueous extract of M.indica and A.heterophyllus has more scavenging activity against superoxide radical when compared to individual leaf extracts with 65.9 percentage of inhibition. The Superoxide scavenging capacities of the extracts were represented in Figure 5.

The study of superoxide radical scavenging activity of leaf galls of M.indica by Rajasekaran and Mahimaidoss (2016) showed that the leaf gall extract of $M$. indica has good high radical scavenging activity [25]. The present study also reveals that M.indica also has significant superoxide scavenging activity with percentage inhibition of $61.1 \%$ at a concentration of $100 \mathrm{mg} / \mathrm{ml}$. 
Figure 5: Superoxide radical activity of M.indica and A.heterophyllus and Combined extract

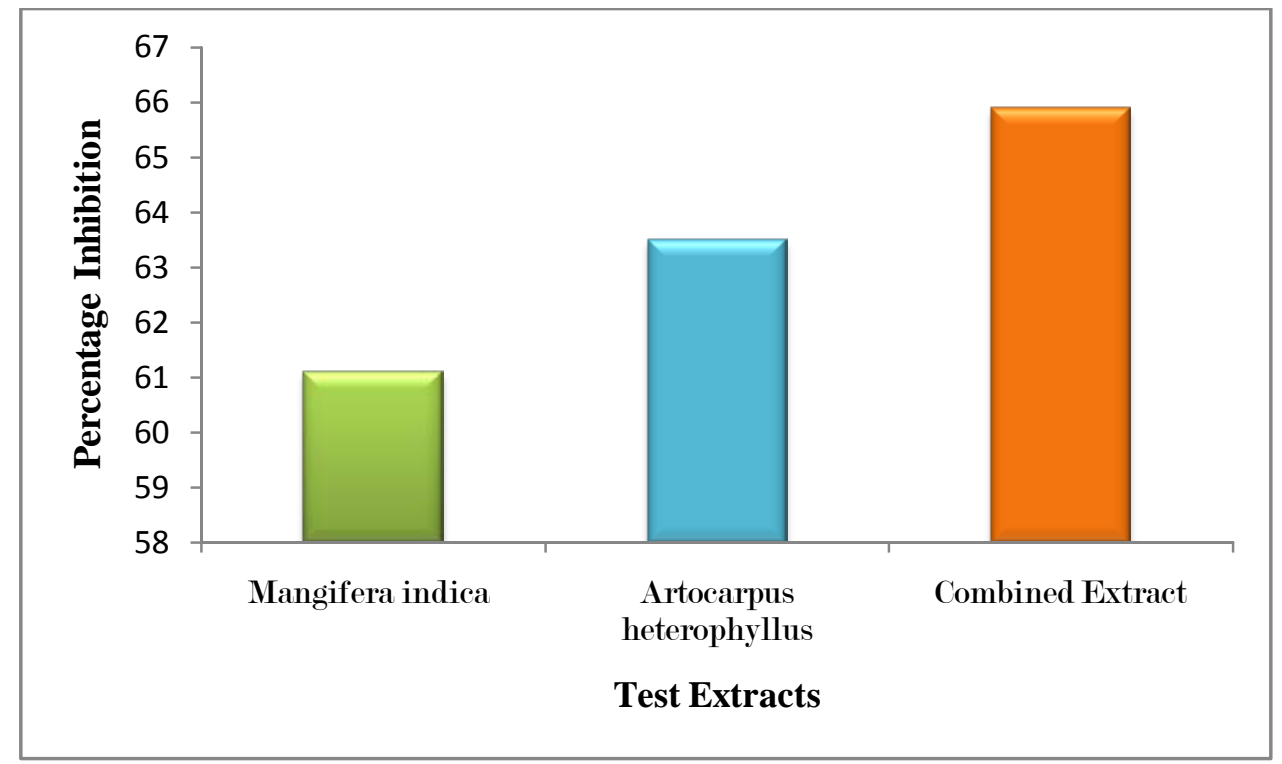

Total Antioxidant Assay:

Total Antioxidant activities of the three extracts were represented in Figure 6.

Figure 6: Total Antioxidant activity of M.indica and A.heterophyllus and Combined extract

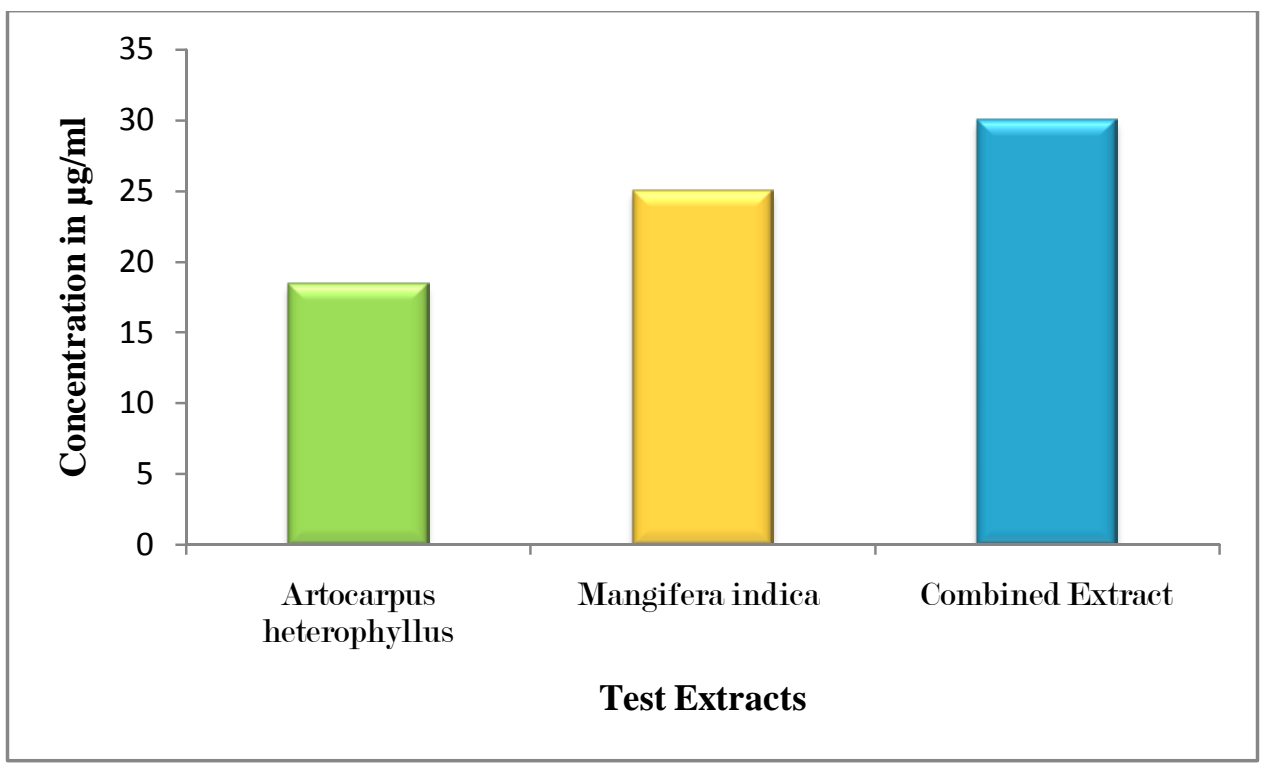


Total antioxidant capacity of the extracts was calculated by using percentage of inhibition against concentration of ascorbic acid. At $500 \mu \mathrm{g} / \mathrm{ml}$ concentration, aqueous Combined extract exhibited $30 \%$ inhibition which is greater when compared to $M$. indica and A. heterophyllus extract.

The study of Sreeja et al., 2021 and Ocampo et al., 2020 reveal that the other parts of $M$. indica and A. heterophyllus also exhibit significant total Antioxidant activity [26] [27]. Combined extract exhibited good antioxidant activity and can be used to treat harmful effects caused by free radicals which lead to diseases like cancer.

\section{Antimicrobial activity}

The antimicrobial activity of the leaf extracts of Mangifera indica and Artocarpus heterophyllus and Combined extract were evaluated against the bacterial species Escherichia coli, Staphylococcus aureus, Pseudomonas aeruginosa and Klebsiella pneumonia using disc diffusion method. Antibiotic disc (Levofloxacin 30mg) was used as a positive control. Evaluation of antibacterial activity of these plant extracts was recorded in Table 2 and illustrated in Figure 7.

The results revealed that all plant extracts were potentially effective in suppressing microbial growth of bacterial species with variable potency. $M$. indica was the most effective extract retarding microbial growth of all tested pathogenic bacteria at concentration of $20 \mu$ l while Combined extract was very less effective against all bacterial species.

Table 2: Antimicrobial activity of M.indica and A.heterophyllus and Combined extract

\begin{tabular}{|l|c|c|c|c|c|}
\hline \multirow{2}{*}{ Organism } & & \multicolumn{4}{|c|}{ Zone of Inhibition } \\
\cline { 2 - 6 } & M. indica & A.heterophyllus & $\begin{array}{l}\text { Combined } \\
\text { Extract }\end{array}$ & Disc & Dis. $\mathrm{H}_{2} \mathrm{O}$ \\
\hline E.coli & $3 \mathrm{~mm}$ & $2 \mathrm{~mm}$ & $1 \mathrm{~mm}$ & $3 \mathrm{~mm}$ & - \\
\hline S.aureus & $6 \mathrm{~mm}$ & $4 \mathrm{~mm}$ & $3 \mathrm{~mm}$ & $2 \mathrm{~mm}$ & - \\
\hline K.pneumoniae & $6 \mathrm{~mm}$ & $4 \mathrm{~mm}$ & $3 \mathrm{~mm}$ & $2 \mathrm{~mm}$ & - \\
\hline P.aeruginosa & $7 \mathrm{~mm}$ & $5 \mathrm{~mm}$ & $1 \mathrm{~mm}$ & $2 \mathrm{~mm}$ & - \\
\hline
\end{tabular}


Figure 7: Zone of Inhibition of the Extracts

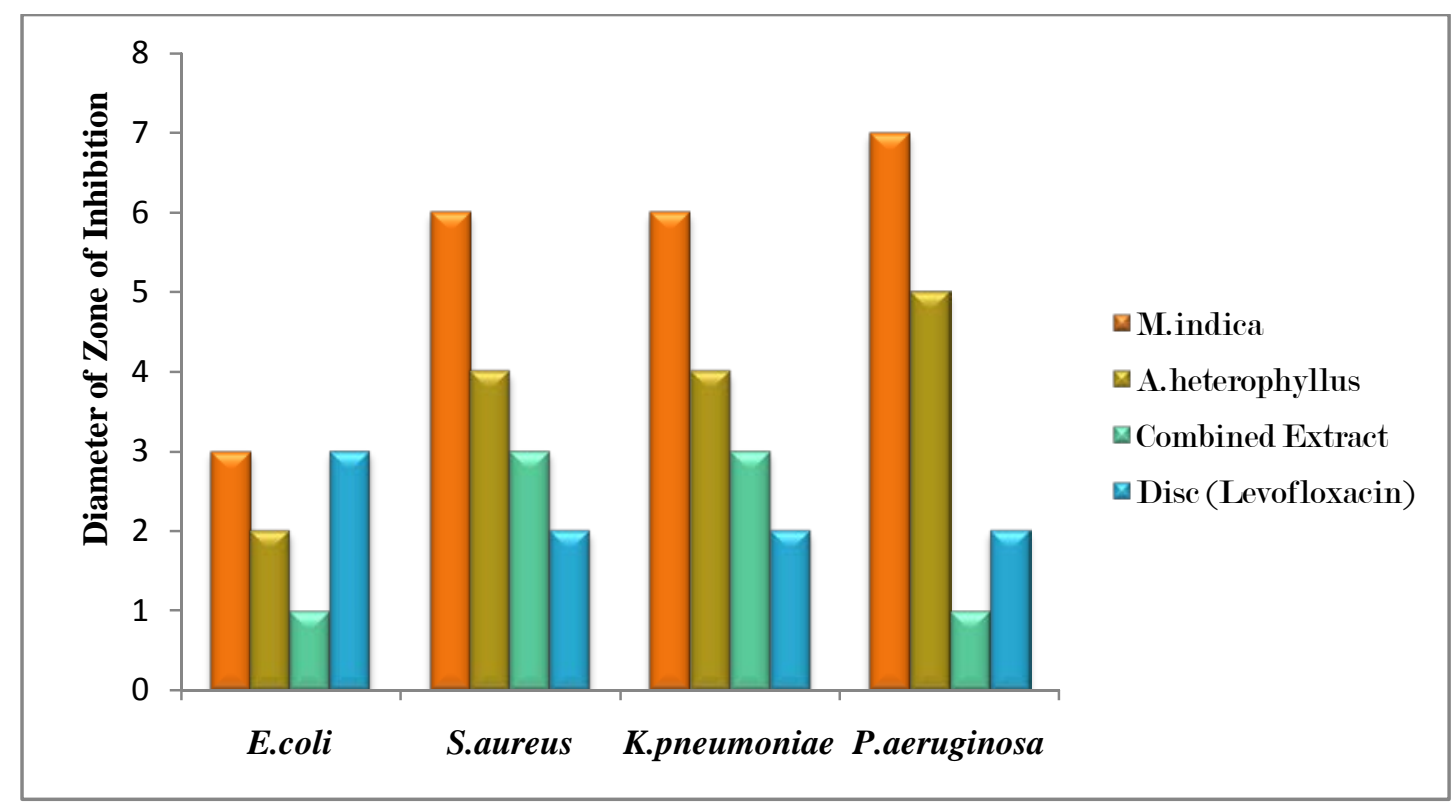

The results are in accordance with the Comparison of antibacterial activity of leaves extracts of Tectona grandis, Mangifera indica, and Anacardium occidentale investigated by Krishnananda and Ramakrishna, 2017 which showed that ethanol extracts of $M$. Indica and A. Occidentale were effective against all test concentrations $(25 \mathrm{mg} / \mathrm{ml})$ [28].

Summary and Conclusion

Various parts of Mangifera indica and Artocarpus heterophyllus species have been reported to have medicinal benefits and used in traditional medicine. They are shown to have many important biological properties which can be used in treatment of various diseases. The present study showed that the Combination of both extracts have significant antioxidant and antibacterial activity. The presence of important phyto-constituents such as alkaloids, flavonoids, phenols, saponins, steroids, etc may be responsible for their potent biological properties.

The present study results conclude that the Combined extract of $M$. indica and A. heterophyllus can be used as a good source of antioxidants to protect against various diseases. The Combined extract can be further studied against different cancer cell lines to test its potency. 


\section{Acknowledgement}

The authors are grateful to Department of Biochemistry, Sri Ramakrishna College of Arts and Science for Women, Centre for Bioscience and Nanoscience Research, Botanical Survey of India Coimbatore for providing needed assistance.

\section{Reference}

1. Swaroop A, Bagchi M, Moriyama H,et al.Health Benefits of Mango (Mangiferaindica L) and Mangiferin Japan Journal of Medicine. 2018; 1:2.

2. Gupta D, Mann S, Sood A, Gupta RK, Phytochemical, nutritional and antioxidant acitivity evaluation of seeds of jackfruit (Artocarpus heterophyllus L.). Int J Pharma Bio Sci, 2 (2011) 336.

3. K. Shanmugapriya, P. S. Saravana, H. Payal, S. Peer Mohammed, and W. Binnie, “Antioxidant activity, total phenolic and flavonoid contents of Artocarpus heterophyllus and Manilkara zapota seeds and its reduction potential,” International Journal of Pharmacy and Pharmaceutical Sciences, vol. 3, no. 5, pp. 256-260, 2011.

4. Lengbiye E. Moke, Koto-te-Nyiwa Ngbolua, Gédéon N. Bongo , Lin M. Messi , Olivier P. Noté , Joséphine N. Mbing , Pius T. Mpiana (2017). Artocarpus heterophyllus Lam. (Moraceae): Phytochemistry, Pharmacology and Future Directions, a mini-review. J. of Advanced Botany and Zoology. Vol 5 (3). DOI: 10.5281/zenodo.1019850.

5. Sunyong Yoo , Kwansoo Kim, Hojung Nam and Doheon Lee. Discovering Health Benefits of Phytochemicals with Integrated Analysis of the Molecular Network, Chemical Properties and Ethnopharmacological Evidence. Nutrients.2018 Aug; 10 (8); 1042.

6. Khoushika Rajshree R, Chitra P. A comparative study on the in vitro antiinflammatory and antibacterial activities in the leaf extracts of Costus igneus and Mangifera indica. Int J Curr Res 2016; 8(8):36714-36722.

7. Keerthana M, Chitra P. Antidiabetic Activity of Chemical Constituents in Elaeocarpus Tectorius Fruits - An In Silico Study. Journal of University of Shanghai for Science and Technology.2020; 22 (12): 342-358.

8. Deepak M. Kasote, Surendra S. Katyare, Mahabaleshwar V. Hegde and Hanhong Bae. Significance of Antioxidant Potential of Plants and its Relevance to Therapeutic Applications. Int J Biol Sci. 2015; 11(8): 982-991.

9. Asma’a Al-Rifai, Ahmad Aqel, Tarfah Al-Warhi, Saikh M. Wabaidur, Zeid A. Al-Othman and A. Yacine Badjah-Hadj-Ahmed. Antibacterial, Antioxidant Activity of Ethanolic Plant Extracts of 
Some Convolvulus Species and Their DART-ToF-MS Profiling. Evidence-Based Complementary and Alternative Medicine. Volume 2017. Article ID 5694305.

10. K. Santhi and R. Sengottuvel. Qualitative and Quantitative Phytochemical analysis of Moringa concanensis Nimmo. Int.J.Curr.Microbiol.App.Sci (2016) 5(1): 633-640.

11. Thilagavathi. T, Arvindganth. R, Vidhya. D, Dhivya. R. Preliminary Phytochemical Screening of Different Solvent mediated medicinal plant extracts evaluated. Int. Res. J. Pharm. 2015; 6(4): 246-248.

12. Velavan S. (2015) Phytochemical Techniques - A Review. World Journal of Science and Research. 2015; 1(2): 80-91.

13. Rehman TU, Kanwal Z, Zeb MA, Liaqat W, Khan S \& Xiao WL. Phytochemical analysis, antibacterial, antifungal and insecticidal activity of Berberis royleana roots. Pharm. Bioprocess. (2018) 6(3), 132-137.

14. Prabhavathi R. M., Prasad M. P. and Jayaramu M. Studies on Qualitative and Quantitative Phytochemical Analysis of Cissus quadrangularis. Advances in Applied Science Research, 2016, 7(4):11-17.

15. Noor Nazirahanie Abrahim, M S Kanthimathi and Azlina Abdul-Aziz. Piper betle shows antioxidant activities, inhibits MCF-7 cell proliferation and increases activities of catalase and superoxide dismutase. BMC Complementary and Alternative Medicine 2012 12:220.

16. Anandhi Eswaran, Suriyavathana Muthukrishnan, Kavitha Rani Mari, Punithavathi Manogaran. Phytochemical analysis and free radical scavenging activity of green-synthesizedliv-pro-08 formulation. RJLBPCS 2019. 5(1): 613 - 625.

17. Kumar A, Dutt S, Bagler G, Ahuja PS, Kumar S. Engineering a thermo-stable superoxide dismutase functional at sub-zero to $>50^{\circ} \mathrm{C}$, which also tolerates autoclaving. Sci Rep. 2012; 2:387.

18. Hanafey F. Maswada. Assessment of Total Antioxidant Capacity and Antiradical Scavenging Activity of Three Egyptian Wild Plants. J. Med. Sci., 2013; 13 (7): 546-554.

19. Jesteena, Johney, Radhai, Sri, S., Ragunathan, R., J. P. Appl. Micro, 2018, 12(3), 1631-1640.

20. Mohammed, A. H., Na'inna, S. Z., Yusha’u, M., Salisu, B., Adamu, U. and Garba, S.A. Phytochemical Screening and Antibacterial Activity of Mangifera indica Extracts. UMYU Journal of Microbiology Research. Volume 1 Number 1 December, 2016.

21. Rupasinghe HPV, Balasuriya N, Wang Y. Prevention of Type 2 Diabetes by Polyphenols of Fruits. Nutritional Antioxidant Therapies: Treatments and Perspectives 2017; 447-466. 
22. Fitmawati Fitmawati Esi Resida, Sri Nur Kholifah, Rodesia Mustika Roza, Muhammad Almurdani, Emrizal Emrizal. Phytochemical screening and antioxidant profiling of Sumatran wild mangoes (Mangifera spp.): a potential source for medicine antidegenerative effects. Version 3. F1000 Res. 2020; 9:220.

23. Kumar, S., Sandhir, R. \& Ojha, S. Evaluation of antioxidant activity and total phenol in different varieties of Lantana camara leaves. BMC Res Notes 7, 560 (2014). https://doi.org/10.1186/17560500-7-560.

24. Mohan CG, Deepak M, Viswanatha GL, Savinay G, Hanumantharaju V, Rajendra CE, Praveen D Halemani. Anti-oxidant and anti-inflammatory activity of leaf extracts and fractions of Mangifera indica. Asian Pacific Journal of Tropical Medicine (2013), 311-314.

25. Anitha Rajasekaran and Mercy Mahimaidoss. In vitro Antioxidant Activity in Leaf Galls OF Mangifera Indica L. Asian J Pharm Clin Res, Vol 9, Suppl. 1, 2016, 198-201.

26. P. S. Sreeja Devi, Neethu S. Kumar and K. K. Sabu. Phytochemical profiling and antioxidant activities of different parts of Artocarpus heterophyllus Lam. (Moraceae): A review on current status of knowledge. Future Journal of Pharmaceutical Sciences (2021) 7:30.

27. Ocampo, E.T.M., Libron, J.A.M.A., Guevarra, M.L.D. and Mateo, J.M.C. Phytochemical screening, phenolic acid profiling and antioxidant activity analysis of peels from selected mango (Mangifera spp.) genotypes in the Philippines. Food Research 4 (4) (2020) 1116 - 1124.

28. Krishnananda Kamath K, A Ramakrishna Shabaraya. Comparison of antibacterial activity of leaves extracts of Tectona grandis, mangifera Indica, and Anacardium Occidentale. Int J Curr Pharm Res 2017; 9(1):36-39. 